\title{
Synthesis of biodegradable films obtained from rice husk and sugarcane bagasse to be used as food packaging material
}

\author{
Himanshu Gupta ${ }^{1}$, Harish Kumar ${ }^{1}$, Mohit Kumar ${ }^{1}$, Avneesh Kumar Gehlaut ${ }^{1}$, Ankur Gaur ${ }^{{ }^{\dagger}}$, \\ Sadhana Sachan ${ }^{1}$, Jin-Won Park ${ }^{2}$ \\ ${ }^{1}$ Department of Chemical Engineering, Motilal Nehru National Institute of Technology, Allahabad-211004, India \\ ${ }^{2}$ Department of Chemical and Biomolecular Engineering Yonsei University, 262, Seoul 03722, Republic of Korea
}

\begin{abstract}
The current study stresses on the reuse of waste lignocellulose biomass (rice husk and sugarcane bagasse) for the synthesis of carboxymethyl cellulose (CMC) and further conversion of this CMC into a biodegradable film. Addition of commercial starch was done to form biodegradable film due to its capacity to form a continuous matrix. Plasticizers such as Glycerol and citric acid were used to provide flexibility and strength to the film. Biopolymer film obtained from sugarcane bagasse CMC showed maximum tensile strength and elongation in comparison to the film synthesized from commercial CMC and $\mathrm{CMC}$ obtained from rice husk. It has been observed that an increase in sodium glycolate/NaCl content in CMC imposed an adverse effect on tensile strength. Opacity, moisture content, and solubility of the film increased with a rise in the degree of substitution of CMC. Therefore, CMC obtained from sugarcane bagasse was better candidate in preparing biopolymer/biocomposite film.
\end{abstract}

Keywords: Biopolymer Film, Carboxymethyl cellulose (CMC), Citric acid (CA), Glycerol

\section{Introduction}

Today millions of tons of plastics are generated every year throughout the globe and both manufacturing and consumption continues to rise, this rise has developed severe environmental issues [1]. Many attempts have been made to acquire an environmentally friendly material to fix the problems associated with the plastic waste. Most of the research focuses on replacing petro-based plastic with biodegradable products with comparable characteristics and low price [2]. Around 322 million tons of plastics were produced worldwide in 2015. India manufactured 8.3 million tons in 2014-2015, but about $1 \%$ of plastics have been replaced by the biodegradable polymer [3]. In recent years, food packaging has got a lot of attention as a market for biodegradable films. These products will help to reduce environmental pollution in long term [4]. Natural polysaccharides are increasingly attracting researcher attention as they are abundant, viable, eco-friendly, non-toxic, biodegradable, and biocompatible [5]. Researchers are focusing on producing biodegradable films based on polysaccharides as a substitute to regularly used plastic films which are achieved from petrochemical sources to reduce overall environmental impact [6, 7]. This study focuses on the different materials such as commercial carboxymethylcellulose (CMC) obtained from the market and lab-made CMCs obtained from biomass like sugarcane bagasse (SCB) and rice husk. The impact of starch has also been studied on properties of CMC biofilm. Biopolymer films are broadly used in the pharmaceutical industries, packaging, and agriculture. Cellulose exists in both amorphous and crystalline nature due to the existence of hemicellulose and lignin in a complex polymer matrix [8, 9]. Cellulose is linear in shape and high-molecular-weight polymer and due to the presence of intermolecular and intramolecular- $\mathrm{OH}$ bonding; it barely mixed freely in common solvents. CMC is highly water-soluble polysaccharide formed by mercerization (sodium hydroxide) and etherification (Monochloroacetic acid) process [10, 11]. CMC is white in color, odorless, tasteless, non- toxic, free-flowing powder, biodegradable, biocompatible, hydrophilic, and good film forming agent [12, 13]. The linear chain of CMC is commonly used in oil detergents, exploration, paper products, cosmetics, textile, and food industries [14-16]. CMC has the polymeric configuration and a high molecular weight that ex-
This is an Open Access article distributed under the terms of the Creative Commons Attribution Non-Commercial License (http://creativecommons.org/licenses/by-nc/3.0/) which permits unrestricted non-commercial use, distribution, and reproduction in any medium, provided the original work is properly cited.
Received May 7, 2019 Accepted July 20, 2019

${ }^{\dagger}$ Corresponding author

Email: ankur@mnnit.ac.in

Tel: +91-9910068765

Copyright (C) 2020 Korean Society of Environmental Engineers 
hibits thermal gelation, and it is capable of forming filled in bio-composite films. To increase the water resistance and tensile strength (TS) of the starch-based films, CMC was used in most of the problems [2]. Starch is also one of the most important polysaccharides, as it is reusable, a relatively economical natural polymer. It is commonly used to form decomposable films because of its ability to form a continuous matrix. Starch is hydrophilic and suffers from poor mechanical properties that make it unattractive under different environmental conditions as compared to other synthetic polymers. Starch offers both poor mechanical properties and poor water resistance [17]. The citric acid (CA) having multi carboxyl cross-linking improves the water barrier and mechanical properties of the films $[18,19]$. Starch modification with crosslinking is commonly used in the food industry to produce nutritionally beneficial effects and restricted swelling [20]. In plasticizers, molecular volume increases due to reducing in internal hydrogen bonding between polymer chains, and hence, it increases the flexibility of films [21]. Olive oil and fatty acids are introduced to increase the water barrier in the film emulsion [22]. Glycerol is hydrophilic, decreases intermolecular forces between plasticizer and increases the movement of polymer chains, a procedure mostly used to increase the flexibility and extensibility of biodegradable films [23]. In this paper, biopolymer film is prepared from Commercial as well as lab-made CMCs extracted from different biomass sources. The main objective of this work was to make the comparative study between Starch-Commercial CMC and Starch-Lab made CMCs prepare biopolymer film.

\section{Materials and Methods}

\subsection{Raw Material}

Commercial CMC, which is purchased from the market, having a higher molecular weight in the range $\left(\mathrm{M}_{\mathrm{w}}=10,000 \mathrm{Da}, \mathrm{DS}=\right.$ 0.51) was acquired from Molychem. We manufactured CMCs from rice husk and SCB by using Sodium Chlorite, Monochloroacetic acid, Sulfuric Acid, Acetic Acid, Sodium Hydroxide, Potassium hydroxide, 2,7-dihydroxynaphthalene (Merck), Sodium chlorite (Sigma Aldrich), ethanol (Merck) and Hydrochloric Acid (Merck). These chemicals were purchased from the local market in Allahabad, India. Plasticizer film formed using Starch (SRL), glycerol (Rankem), citrus acid (Merck). The chemicals used for the characterization of CMC are Methanol (Merck), nitric acid (Sigma Aldrich), glacial acetic acid (Merck), Glycolic acid (Rankem), sodium chloride (Merck) and Acetone (Merck).

\subsection{Isolation of Cellulose from Rice Husk}

\subsubsection{Moisture removal and milling}

The collected rice husk was first washed with distilled water and then placed in an oven at $70^{\circ} \mathrm{C}$ for $16 \mathrm{~h}$. After that, the rice husk was crushed in a grinder and sieved through a 60-mesh screen.

\subsubsection{Alkali treatment}

Alkali treatment using potassium hydroxide (instead of sodium hydroxide) was done to remove silica present in the rice husk. It also removed some part of lignin and hemicellulose. $100 \mathrm{~g}$ of screened out rice husk was mixed with potassium hydroxide $(6 \%$ $\mathrm{w} / \mathrm{v}$ ) and constantly stirred at $85^{\circ} \mathrm{C}$ for $2 \mathrm{~h}$. After the alkaline treatment, the biomass fibers were washed, filtered, and dried overnight in an oven at $70^{\circ} \mathrm{C}$.

\subsubsection{Acid hydrolysis}

Acid hydrolysis empowers removal of the amorphous regions of cellulose fibers. This affects the fibers morphology, thermal stability, structure, and crystallinity [24]. After the alkaline treatment, the lignin and other impurities remaining in the fibers were removed by acid hydrolysis with dilute $\mathrm{H}_{2} \mathrm{SO}_{4}(4 \% \mathrm{v} / \mathrm{v})$ and stirred at $85^{\circ} \mathrm{C}$ for 2-2.5 $\mathrm{h}$. The treated biomass fibers were washed and filtered with distilled water then after the fibers were dried for the whole night in an oven at $70^{\circ} \mathrm{C}$.

\subsubsection{Bleaching}

Bleaching of Rice husk was done for $4 \mathrm{~h}$ using sodium chlorite $(3 \% \mathrm{w} / \mathrm{v})$ at $80^{\circ} \mathrm{C}$ for removing coloring components. The bleaching procedure was kept at $\mathrm{pH}$ 3-4 by adding an appropriate quantity of acetic acid. After washing with distilled water, white cellulose fibers were dried for the whole night in an oven at $70^{\circ} \mathrm{C}$.

\subsection{Isolation of Cellulose from SCB}

\subsubsection{Moisture removal and size reduction}

First, $500 \mathrm{~g}$ of SCB was drenched in distilled water for $1 \mathrm{~d}$ to eliminate extractives that are easily soluble in water and dried in an oven at $70^{\circ} \mathrm{C}$ for $2 \mathrm{~d}$. After that, SCB was crushed and passed through a 60-mesh size screen.

\subsubsection{Alkali treatment}

$2 \% \mathrm{NaOH}$ was mixed with $50 \mathrm{~g}$ of bagasse (dry basis) before feeding it to the reactor at $80^{\circ} \mathrm{C}$ for $2-2.5 \mathrm{~h}$. The treated SCB biomass fibers were washed and filtered with distilled water then after the fibers were dried for the whole night in an oven at $70^{\circ} \mathrm{C}$.

\subsubsection{Acid hydrolysis}

After the alkaline treatment, the lignin and other impurities remaining in the fibers were removed by acid hydrolysis with dilute $\mathrm{H}_{2} \mathrm{SO}_{4}(4 \% \mathrm{v} / \mathrm{v})$ and stirred at $85^{\circ} \mathrm{C}$ for $2-2.5 \mathrm{~h}$. The treated SCB biomass fibers were washed and filtered with distilled water to attain $\mathrm{pH} 7$ and then dried for the whole night in an oven at $70^{\circ} \mathrm{C}$

\subsubsection{Bleaching}

Degree of whiteness was obtained by using sodium chlorite (4\% $\mathrm{w} / \mathrm{v}$ ) at $80^{\circ} \mathrm{C}$ for $4 \mathrm{~h}$. The $\mathrm{pH}$ was kept in the range of 3 to 4 during the bleaching process. The $\mathrm{pH}$ was controlled by adding acetic acid. After washing, white cellulose fibers were dried for the whole night in an oven at $70^{\circ} \mathrm{C}$.

\subsection{Preparation of CMC from Rice Husk and SCB Cellulose}

The cellulose made from rice husk and SCB waste were dried for $1 \mathrm{~h}$ in an oven at $70^{\circ} \mathrm{C}$, and after that to avoid the moisture, it was put into the desiccator. There are dual phases for the preparation of CMC. The 1st phase is mercerization then the 2nd one is etherification. Mercerization was done to increase strength and for a lustrous appearance. 

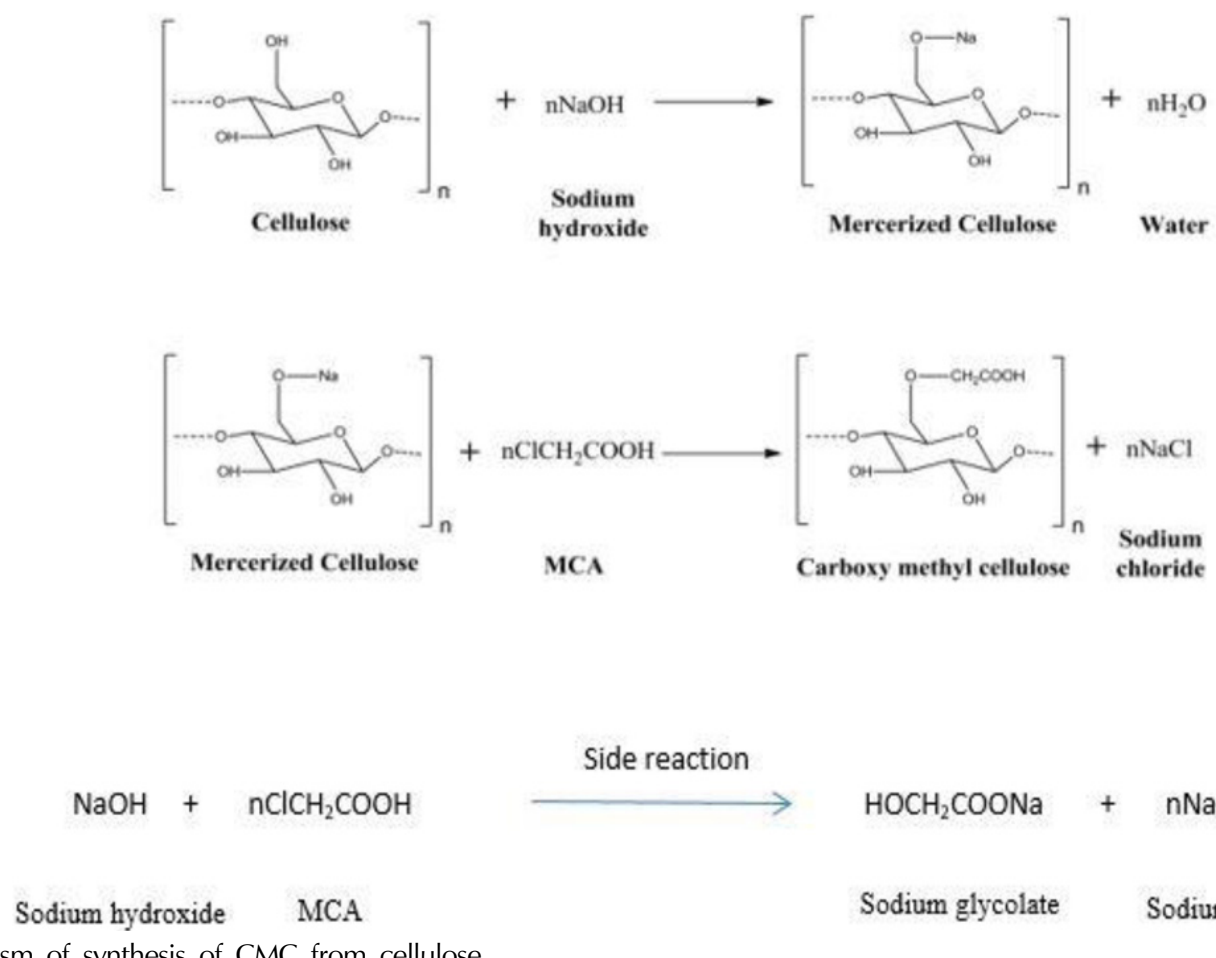

Side reaction

Fig. 1. Mechanism of synthesis of CMC from cellulose.

\subsubsection{Mercerization}

Mercerization was done by taking $10 \mathrm{~g}$ of each cellulose samples obtained from Rice husk and SCB waste in two different beakers. $100 \mathrm{~mL}$ of isopropanol and $20 \% \mathrm{w} / \mathrm{v} \mathrm{NaOH}$ was added to each cellulose sample. The mixture was stirred for 2.5 to $4 \mathrm{~h}$ from $50^{\circ} \mathrm{C}$ to $60^{\circ} \mathrm{C}$ then after the sample was washed and filtered with an appropriate amount of distilled water up to the $\mathrm{pH}$ reached 6.5-7. The washed alkaline fibers were cleaned and kept in an oven for $3.5-4 \mathrm{~h}$ at $70^{\circ} \mathrm{C}$, and then it was referring for 2 nd phase etherification process.

\subsubsection{Etherification}

The product of mercerization mixed with $100 \mathrm{~mL}$ of $20 \%$ Mono-chloroacetic acid (MCA) solution and stirred for 2.5 to 4 $\mathrm{h}$ from $50^{\circ} \mathrm{C}$ to $60^{\circ} \mathrm{C}$. After the completion of the $2^{\text {nd }}$ phase reaction, the sample was washed and filtered with ethanol and $\mathrm{HCl}$ mixture (mixed in the same capacity). The salt formed during side reaction was neutralized by ethanol and remaining $\mathrm{HCl}$ neutralized by $\mathrm{NaOH}$ present in the etherification reaction [10]. The remnant left on the filter paper was $\mathrm{CMC}$, which was dried for the whole night in an oven at $60^{\circ} \mathrm{C}$ for further characterization. The schematic procedure for the production of carboxymethyl cellulose (CMC) from cellulose is shown in Fig.1.

\subsection{Production of Biopolymer Film}

\subsubsection{CMC-Starch blended film}

1g CMCs was mixed in $75 \mathrm{~mL}$ of water at $70^{\circ} \mathrm{C}$ for $15 \mathrm{~min}$. Separately $1 \mathrm{~g}$ starch was added $\left(25^{\circ} \mathrm{C}\right.$ for $\left.10 \mathrm{~min}\right)$ in $100 \mathrm{~mL}$ of water and glycerol (40 mL/100 g starch) and 0.5 CA $10 \%$ (w/w starch). These mixtures were shaking by the stirrer for $20 \mathrm{~min}$ at $85^{\circ} \mathrm{C}$. The CMCs and Starch mixer were added side by side $(75 \mathrm{~mL}$ CMCs solution $+100 \mathrm{~mL}$ CA-Starch solution) and continuously stirred at $70^{\circ} \mathrm{C}$ for $15 \mathrm{~min}(\mathrm{pH}=5.5)$. After the solution mixed for $20 \mathrm{~min}$ at $40^{\circ} \mathrm{C}$ to distinct all air bubbles. Then, $70 \mathrm{~mL}$ of solution was discharged into a Petri dish and then dried for a whole night at $55^{\circ} \mathrm{C}$ in an oven to cast blended films. The whole process is shown in Fig. 2(a) and (b).

\subsubsection{Degree of substitution (DS)}

DS is the number of $-\mathrm{OH}$ group that was substituted by $-\mathrm{CH}_{2}-\mathrm{COOH}$ group in the cellulose configuration at $\mathrm{C}_{2}, \mathrm{C}_{3}$, and $\mathrm{C}_{6}$ position [12]. For determining DS of CMC, $2 \mathrm{~g}$ of moisture-free CMCs samples obtained from rice husk and SCB were taken in two different beakers and marked them accordingly. After that, $15 \mathrm{~mL}$ of $70 \% \mathrm{v} / \mathrm{v}$ methanol-water solution were added in each beaker, mix them well, and allowed them to stand for 15-20 min. Then $200 \mathrm{~mL}$ of distilled water and $50 \mathrm{~mL}$ of $0.5 \mathrm{~N}$ sodium hydroxide were added to each beaker and stirred for $4 \mathrm{~h}$. Quantity of unreacted $\mathrm{NaOH}$ present in each beaker was titrated against $0.4 \mathrm{~N}$ solution of $\mathrm{HCl}$ by adding phenolphthalein as an indicator. The readings of the quantity of $\mathrm{HCl}$ needed for the titration were used in Eq. (1), to calculate the DS.

$$
\mathrm{DS}=\frac{(0.162 \times \mathrm{B})}{(1-0.058 \times \mathrm{B})}
$$

Where

$\mathrm{B}=$ milli-equivalents of total carboxyl groups per $\mathrm{g}$ of sample taken and is calculated using Eq. (2).

$$
\mathrm{B}=\frac{(\mathrm{mL} \text { of } \mathrm{NaOH} \times \text { Normality of } \mathrm{NaOH})-(\mathrm{mL} \text { of } \mathrm{HCl} \times \text { Normality of } \mathrm{HCl})}{\text { grams of sample }}(2)
$$




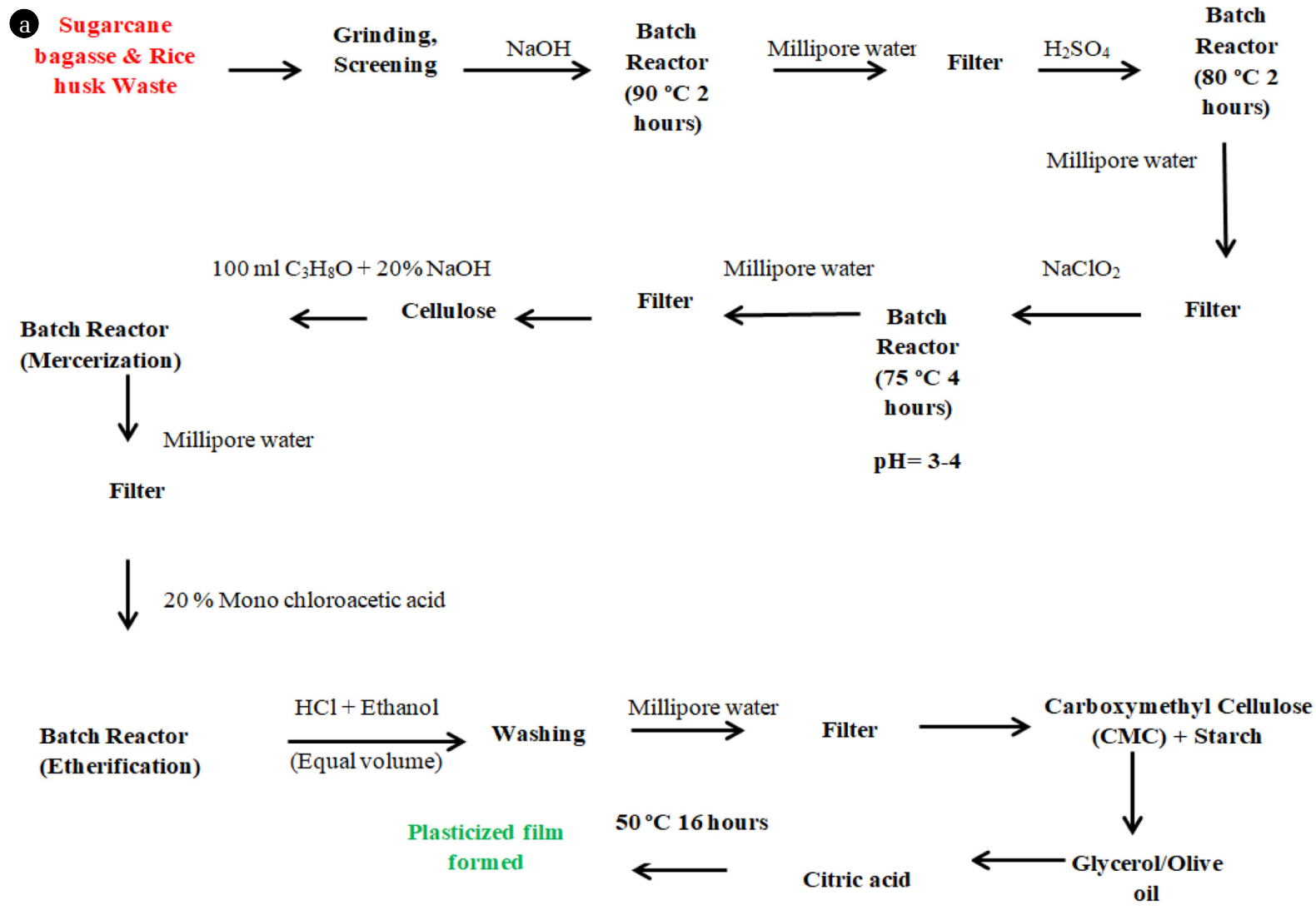

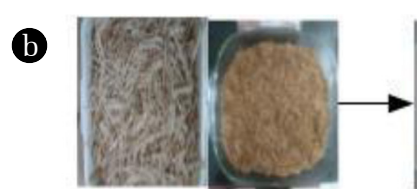

Lignocellulosic b iomass

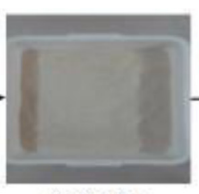

Grinding and screening

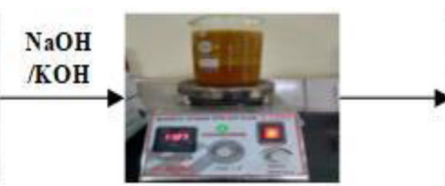

Alkali treatment

Citric acid

Reactor

$\left(80^{\circ} \mathrm{C} 2\right.$

hours)

Millipore water

$\mathrm{NaClO}_{2}$

\section{$\mathrm{NaClO}_{2}$}

Batch

$5^{\circ} \mathrm{C} 4$

$\mathrm{pH}=3-4$

oil

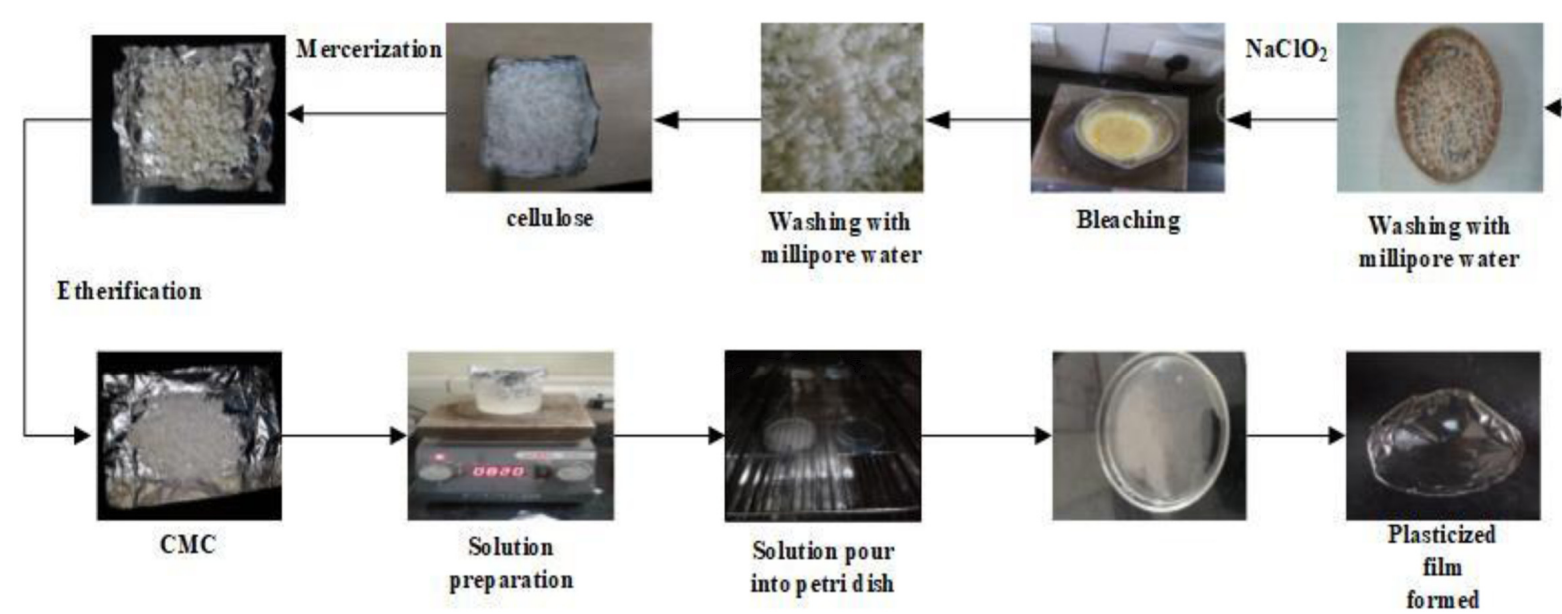

Fig. 2. (a) Preparation of bioploymer film from lab made CMC, (b) Preparation procedure of bioploymer film from lab made CMC. 


\subsubsection{CMC yield}

CMC yield was an estimate on the dry weight basis, and the total dry weight of $\mathrm{CMC}$ was an estimate as per the subsequent equation [12].

$$
\text { Yield }=\left(\frac{\text { gram of } \mathrm{CMC}}{1 \mathrm{~g} \text { of cellulose }}\right)
$$

\subsubsection{CMC content}

In $100 \mathrm{~mL}$ of $80 \%$ (methanol-water) solution, $1.50 \mathrm{~g}$ of dried CMCs was mixed. This solution was stirred, then stored for $15 \mathrm{~min}$ and then filtered. The cake on filter paper was washed with newly prepare $100 \mathrm{~mL}$ of $80 \%$ (methanol-water) solution and then dried at $100^{\circ} \mathrm{C}$ to acquire $\mathrm{CMC}$ [16]. The content of CMC was estimated by using Eq. (4).

$$
\text { Where: CMC content }(\%)=\frac{\mathrm{M}_{1}}{\mathrm{M}_{2}} \times 100
$$

$$
\mathrm{M}_{2}=\text { Final dried mass (g), } \mathrm{M}_{1}=\text { Initial dried mass (g) }
$$

\subsection{5. $\mathrm{NaCl}$ content in $\mathrm{CMC}$}

$\mathrm{NaCl}$ content can be determined by adding $2 \mathrm{~g}$ of CMCs in 250 $\mathrm{mL}$ of $65 \%$ (methanol-water) and left for $4 \mathrm{~h} .100 \mathrm{~mL}$ of the aqueous phase was neutralized by diluted nitric acid and titrated by 0.1 $\mathrm{N}$ silver nitrate solutions [16]. By using equation, $5 \mathrm{NaCl}$ content was calculated.

$$
\mathrm{NaCl}(\%)=\frac{1.461 \times \mathrm{P}}{\mathrm{W}}
$$

Where

$\mathrm{P}=$ amount of silver nitrate $(\mathrm{mL})$

$\mathrm{W}=$ weight of the dried sample $(\mathrm{g})$

\subsubsection{Sodium glycolate content}

$5 \mathrm{~mL}$ glacial acetic acid and $5 \mathrm{~mL}$ distilled water were taken in a separate beaker, and $0.50 \mathrm{~g}$ of CMCs was added to each beaker. Then $1 \mathrm{~g}$ sodium chloride and $50 \mathrm{~mL}$ acetone was added and stirred for $20 \mathrm{~min}$ for complete precipitation of CMC mixture [16]. A strong supernatant was used to formulate the test solution after the mixture being filtered. The single reagent was used for the preparation of the reference solution. The reference solution and the test solution were placed in a water bath for $20 \mathrm{~min}$, and acetones were dispatched from both the solution, then after solutions were cooled. After the solution is cooled addition of $20 \mathrm{~mL}$ of 2, 7-dihydroxynaphthalene was done. The wavelength for UV-VIS spectrophotometer was set to $540 \mathrm{~nm}$ for observing the absorbance peaks of the reference solution related to the test solution. Glycolic acid was used to define the unidentified amount of sodium glycolate in the test solution using the following Eq. (6) and plotted calibration curve of the pure standard.

$$
\text { Sodium glycolate } \%=\frac{\mathrm{D} \times 1.29}{\mathrm{C}}
$$

Where 1.29 is a conversion factor for changing glycolic acid into sodium glycolate

$\mathrm{D}=\mathrm{mg}$ of glycolic acid determines from the calibration curve

$\mathrm{C}=$ the dry weight of the sample in $\mathrm{g}$.

\subsection{Characterization of $\mathrm{CMC}$}

Cellulose and CMCs have been characterized by performing XRD and Fourier transforms infrared spectroscopy (FTIR), and accordingly, a comparison was made among them based on their core analysis.

\subsubsection{FTIR}

FTIR shows component variations in the polymer structure. For examination, pellets were produced after crushing the sample with KBR. Spectra were taken on Perkin Elmer Bx11- FTIR Spectrophotometer, in the range of $4,000-400 \mathrm{~cm}^{-1}$.

\subsubsection{Wide-angle X-ray diffraction (XRD) pattern}

The crushed dried samples were compressed into the disks and then measured with an X-ray diffractometer in which patterns were recorded with X-ray diffractometer system using a $\mathrm{Cu} \mathrm{Ka}$ radiation $\left(1 \frac{1 / 4}{1} 1.5406 \AA\right)$ in the $2 \mathrm{q}$ range from $5^{\circ}$ to $70^{\circ}$, worked at $40 \mathrm{~mA}$ and $40 \mathrm{kV}$, and a scanning speed of $10^{\circ} \mathrm{min}^{-1}$.

\subsection{Characterization of Biopolymer Film}

\subsubsection{Moisture content $(\mathrm{MC})$}

Generally, the AOAC method is used for calculating MC [25]. Sample containing $2 \mathrm{~g}$ dry sample to constant weight at $90-100^{\circ} \mathrm{C}$ under pressure less than $100 \mathrm{~mm} \mathrm{Hg}$. Calculate the loss in weight after the material was drying.

\subsubsection{Solubility}

In a hot oven, film specimens were dried at $105^{\circ} \mathrm{C}$ to remove the MC. The dry sample is then weighted and placed with $20 \mathrm{~mL}$ of distilled water in a glass tube. The tubes were covered and placed at room temperature for $1 \mathrm{~d}$ in a shaking water bath. After that, film pieces were removed and dried at $105^{\circ} \mathrm{C}$ in an oven for $1 \mathrm{~d}$ to calculate the film's final dry weight [23].

$$
\text { Solubility } \%=\frac{\text { (initial dry weight) }-(\text { final dry weight })}{\text { initial dry weight }} \times 100
$$

\subsubsection{Film opacity}

Film opacity was estimated by obtaining rectangular strips $(10 \mathrm{~mm}$ $\mathrm{x} 40 \mathrm{~mm}$ ), which were straight placed in the UV-VIS spectrophotometer [26]. The film sample's absorption peak was recorded from 250 to $800 \mathrm{~nm}$. The film opacity in the absorbance spectrum was observed at $600 \mathrm{~nm}$.

\subsubsection{TS}

Films were cut into pieces of dimension $10 \mathrm{~mm}$ wide and $80 \mathrm{~mm}$ long. The mechanical property (TS and elongation) were measured using TENIUS OLSEN machine $250 \mathrm{~N}$ load cell. The cross-head speed and initial grip separation were set between $1 \mathrm{~mm} / \mathrm{min}$ and $40 \mathrm{~mm}$.

\section{Results and Discussion}

\subsection{Characterization of Waste Lignocellulosic Biomass}

The yield of CMCs, DS, $\mathrm{NaCl}$, and Sodium glycolate obtained from 
Table 1. Properties of $\mathrm{CMC}$ and Film Produced from Different Lignocellulosic Biomass

Waste along with Commercial CMC

\begin{tabular}{lccccc}
\hline Biomass waste & Yield of CMC & DS & CMC content (\%) & NaCl content (\%) & Sodium glycolate (\%) \\
\hline Commercial & - & 0.51 & 95.04 & 3.53 & 1.43 \\
Rice husk & 0.8933 & 0.53 & 92.33 & 4.38 & 3.29 \\
Sugarcane bagasse & 0.9457 & 0.65 & 98.53 & 0.87 & 0.6 \\
\hline
\end{tabular}

Properties of Biopolymer film

\begin{tabular}{lcccccc}
\hline Biomass waste & Ratio (Starch:CMC) & Moisture content (\%) & Solubility (\%) & Opacity (\%) & Tensile strength & Elongation (\%) \\
\hline Commercial & $50: 50$ & 11.018 & 27.19 & 5.23 & 11.96 & 12.14 \\
Rice husk & $50: 50$ & 12.57 & 28.11 & 17.28 & 12.72 & 12.69 \\
Sugarcane bagasse & $50: 50$ & 12.83 & 39.56 & 21.23 & 16.03 & 18.97 \\
\hline
\end{tabular}

rice husk and SCB were calculated and shown in Table 1. The amount of the byproduct obtained from SCB ( $\mathrm{NaCl} 0.87 \%$ and Sodium glycolate $0.6 \%$ ) was insignificant in amount as compared to rice husk ( $\mathrm{NaCl} 4.38 \%$ and Sodium glycolate $3.29 \%$ ), an undesired side reaction took place, which dominated the rice husk CMC production and became the reason for this observation [22]. Production of Sodium glycolate leads to the reduction in DS. As the concentration of $\mathrm{NaOH}$ increases, it tends to interrupt the cellulose chain formation by alkaline hydrolysis [27]. Sodium glycolate is poisonous in nature, and the ratio of sodium glycolate and $\mathrm{NaCl}$ content should not be more than $0.5 \%$ in food additives [12]. The purity of lab-made CMC obtained from SCB is $98.53 \%$, which is a much higher purity as compared to Commercial CMC, which stood around $95.04 \%$.

\subsection{XRD Analysis}

XRD was performed to examine the crystallinity of cellulose and CMC extracted from rice husk and SCB formed by Carboxymethylation with $20 \% \mathrm{NaOH}$ and $20 \%$ MCA [10]. Fig. 3(a) and (b) displays the crystalline peaks of cellulose isolated from rice husk and SCB and their synthesized CMC, respectively. In two cases, CMC was synthesized by mercerization with $20 \% \mathrm{w} / \mathrm{v}$

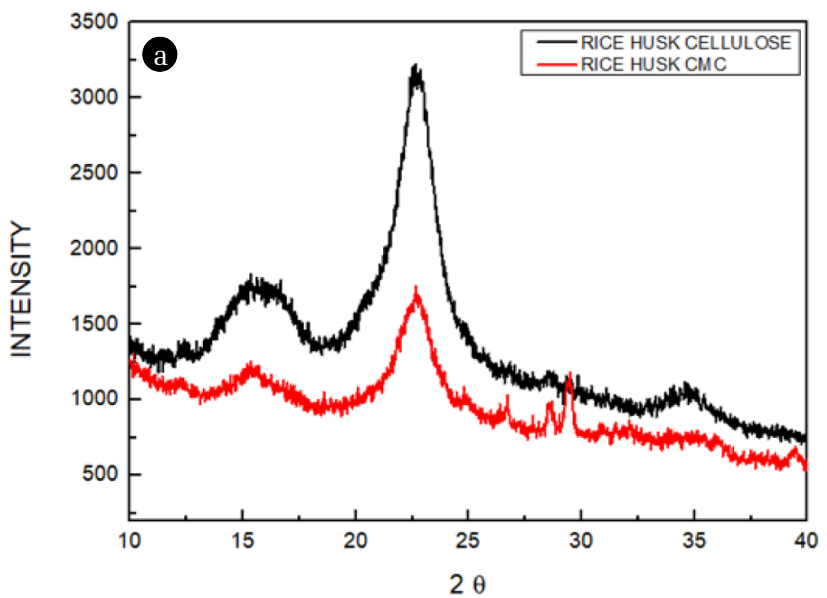

$\mathrm{NaOH}$. In XRD spectra it is visible that the crystalline peaks are stronger in cellulose isolated from rice husk and SCB as compared to spectra exhibited by CMC. XRD type Peak's height \& width were significantly changed due to the breaking of the -OH bond that maintained the crystalline configuration by replacing - $\mathrm{OH}$ by $\left(-\mathrm{CH}_{2}-\mathrm{COOH}\right)$ groups. The decrease in crystallinity is significant in applications, like manufacturing of hydrogels, enhanced capability of CMC to absorb water due to an increase in the amorphous region [28]. Peak heights in XRD spectra of cellulose are greater than peak heights of lignocellulose and CMCs. The CMCs shows less crystallinity than cellulose because, during mercerization, the hydrogen bonding gets ruptured in an alkaline environment. The crystalline peak in XRD spectra of CMCs gets shifted due to the breakage of $\beta-1,4$ glycosidic bonding which is responsible for an increase in the gap among cellulose molecules. A higher DS of CMC results in broader crystallinity peak and a decrease in crystallinity [15].

\subsection{FTIR Analysis}

The CMCs obtained from Rice husk, and SCB was analyzed by FTIR. The spectrum of synthesized CMCs was shown in Fig. 4. The FTIR spectral marked that the broad absorption band in the

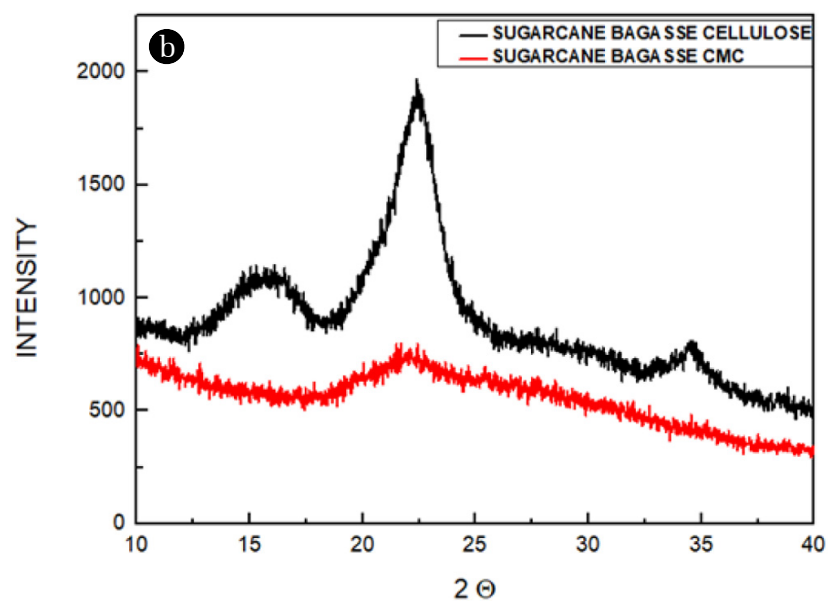

Fig. 3. X-ray Diffractogram of isolated cellulose and CMC from (a) Rice husk (b) Sugarcane bagasse. 


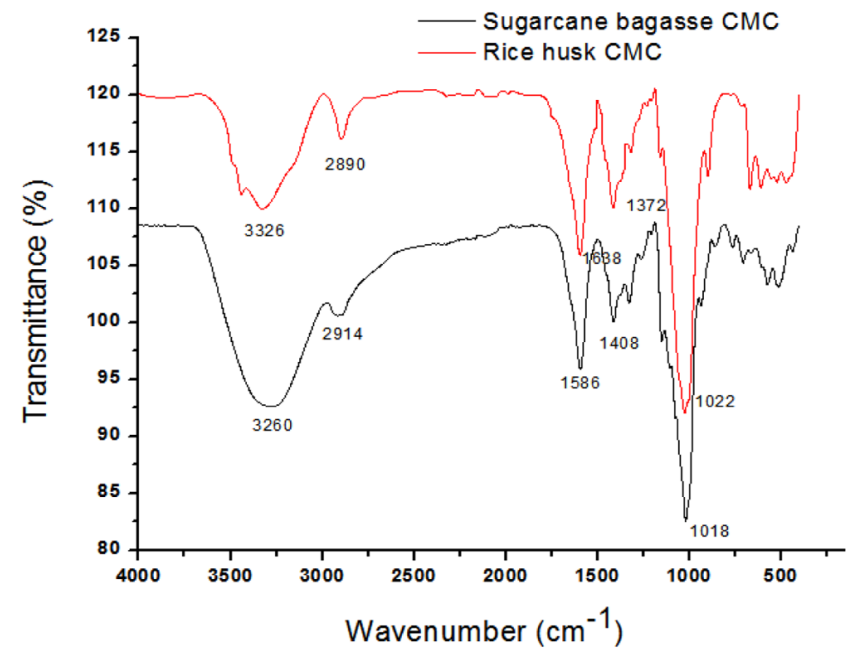

Fig. 4. FTIR spectra of CMC synthesized from Rice husk and Sugarcane bagasse.

rice husk $\left(3,326 \mathrm{~cm}^{-1}\right)$, and SCB $\left(3,260 \mathrm{~cm}^{-1}\right)$ is due to the stretching occurring in the $-\mathrm{OH}$ group [15]. A band at rice husk $(2,890$ $\left.\mathrm{cm}^{-1}\right)$ and SCB $\left(2,914 \mathrm{~cm}^{-1}\right)$ is attributed to C-H stretching vibration. The existence of a new and strong absorption band at rice husk $\left(1,638 \mathrm{~cm}^{-1}\right)$ and $\operatorname{SCB}\left(1,586 \mathrm{~cm}^{-1}\right)$ confirms the stretching vibration of the $-\mathrm{COOH}$ group. Rice husk $\left(1,372 \mathrm{~cm}^{-1}\right)$ and SCB $\left(1,408 \mathrm{~cm}^{-1}\right)$ band are assigned to $-\mathrm{CH}_{2}$ scissoring vibrations [30]. The band around rice husk $\left(1,022 \mathrm{~cm}^{-1}\right)$ and SCB $\left(1,018 \mathrm{~cm}^{-1}\right)$ are assigned to $-\mathrm{OH}$ bending vibration and $\mathrm{C}-\mathrm{O}-\mathrm{C}$ bond stretching [31].

\subsection{Effect of Moisture Absorption, Solubility, and Opacity on Plasticizer Films}

Table 1 shows that the moisture absorption, solubility, and opacity of the CMCs-Starch film. It was found that the absorption of moisture for Starch-Commercial CMC was less than the Starch-Lab made CMCs film, but an increase in DS also increases the moisture absorption capacity. CMC is hydrophilic in nature, but its hydrophilicity is lesser than that of starch [18, 19]. CMC also improves the water resistance capability of starch matrix and form hydrogen bonds with $-\mathrm{OH}$ and $-\mathrm{COOH}$ groups of $\mathrm{CMC}$ to make a strong structure and diminish the diffusion of water molecules. Moisture absorption, solubility, and opacity also increase with an increase in DS and glycerol concentration [22]. This result indicates that starch and CMC combination improves the water resistance [19]. Glycerol is responsible for films flexibility and smooth surface [23, 32]. Due to an increase in free volume, plasticizer mobility increases hence increase the amorphous nature [21]. The film opacity significantly increased with increasing CMC content or DS. CA is acknowledged as a cross-linking agent for starch amendment. CA also increases water barrier and mechanical properties because the presence of the multi-carboxyl structure and can build a stronger bond of hydrogen between the $-\mathrm{OH}$ groups present on starch molecules [2].

\subsection{Effect of the TS and Elongation on Plasticizer Films}

Table 1 shows that DS also affects the TS, and the film composed with CMCs of higher DS have better TS. The DS and TS of rice husk CMC was less than that of SCB; this is due to the presence of high $\mathrm{NaCl}$ and sodium glycolate content in the rice husk [22]. The TS and elongation percentage of these samples could indicate the presence of hydrogen bonds between the CMC chains [19]. The higher CMC content increases film $\mathrm{TS}$ and $-\mathrm{OH}$ bonds between the polysaccharide derivative and cellulose fiber [6]. The biopolymer film synthesized from Starch-Lab made CMCs showed a better result than the biopolymer film prepared with Starch-Commercial CMC. CMC also improved elongation percentage and TS. Table 1 shows that SCB based CMC displayed more TS compared to other lab-made CMC. The cross-linking of starch with CMC molecule increases the intermolecular bonding by introducing covalent bond in term to improve the TS of biopolymer film [19]. Table 2 shows the comparative studies between lab-made CMC (SCB and rice husk) and commercial CMC.

\section{Conclusions}

In this study biopolymer film was produced from CMCs synthesized from different lignocellulosic biomass such as rice husk and SCB. The biopolymer film prepared from blended Starch-Lab made CMC solution showed better mechanical properties TS and Elongation) than the film prepared from blended Starch- Commercial CMC solution. Cross-linking of a starch molecule increases the intermolecular hydrogen bond, which increases in TS. Addition of plasticizers in the film increases the film flexibility and reduces the MC of biopolymer film. The blended film composed of CMC obtained from SCB showed more TS (16.03 MPa) and elongation (18.97\%) as compared to the film composed of CMC obtained from rice husk (TS 12.72 MPa and Elongation 12.69\%) and commercial CMC (TS $11.96 \mathrm{MPa}$ and $12.14 \%$ ). The DS of CMC obtained from SCB is more than the DS of commercial CMC and CMC obtained from rice husk because of less content of sodium glycolate and $\mathrm{NaCl}$. MC, solubility, and opacity of the film increase with an increase

Table 2. Comparative Study between Lab-made CMC and Commercial CMC

\begin{tabular}{lccc|lccc}
\hline \multirow{2}{*}{ Biomass } & \multicolumn{3}{c}{ Previous study } & \multirow{2}{*}{ Biomass } & \multicolumn{3}{c}{ Current study } \\
\cline { 2 - 7 } & DS & TS(MPa) & Elongation (\%) & & DS & TS (MPa) & Elongation (\%) \\
\hline Rice stubble [22] & 0.64 & 3.20 & 4.33 & Rice husk & 0.53 & 12.72 & 12.69 \\
Sugarcane bagasse [33] & 0.45 & 21 & 2 & Sugarcane bagasse & 0.65 & 16.03 & 18.97 \\
Commercial (CMC) [22] & $0.75-0.85$ & 13.87 & 7.54 & Commercial (CMC) & 0.51 & 11.96 & 12.14 \\
\hline
\end{tabular}


in DS of CMC. FTIR and XRD data confirm that CMCs were successfully synthesized. The CMC obtained from SCB can be used to prepare a bio-degradable film because it possesses flexibility, acceptable opacity, and mechanical property for use in the food packaging industry.

\section{Acknowledgment}

On the very outset of this work, I would like to extend my sincere \& heartfelt obligation to CIR, MNNIT Allahabad and Department of Physics, IIT Kanpur who have helped me in this endeavor.

\section{References}

1. Khazaei N, Esmaiili M, Djomeh ZE, Ghasemlou M, Jouki M. Characterization of new biodegradable edible film made from basil seed(Ocimum basilicum L.) gum. Carbohydr. Polym. 2014;102:199-206.

2. Almasi H, Ghanbarzadeh B, Entezami AA. Physicochemical properties of Starch CMC-nonclay biodegradable films. Int. J. Biol. Macromol. 2010;46:1-5.

3. Yadav A, Mangaraj S, Singh R, Das SK, M NK, Arora S. Biopolymers as packaging material in food and allied industry. Int. J. Chem. Stud. 2018;6:2411-2418.

4. Dashipour A, Razavilar V, Hosseini H, et al. Antioxidant and antimicrobial carboxymethyl cellulose films containing zataria multiflora essential oil. 2015;72:606-613.

5. Wang H, Gong X, Miao Y, et al. Preparation and characterization of multilayer films composed of chitosan, sodium alginate and carboxymethyl chitosan-ZnO nanoparticles. Food Chem. 2019;283:397-403.

6. Antosik AK, Wilpiszewska K. Natural composite based on polysaccharide derivatives: Preparation and physicochemical properties. Chem. Pap. 2018;72:3215-3218.

7. Roy N, Saha N, Kitano T, Saha P. Biodegradation of PVP-CMC hydrogel film: A useful food packaging material. Carbohydr. Polym. 2012;89:346-353.

8. Ho MC, Ong VZ, Wu TY. Potential use of alkaline hydrogen peroxide in lignocellulosic biomass pretreatment and valorization - A review. Renew. Sust. Energ. Rev. 2019;112:78-86.

9. Loow Y-L, New EK, Yang GH, Ang LY, Foo LYW, Wu TY. Potential use of deep eutectic solvents to facilitate lignocellulosic biomass utilization and conversion. Cellulose 2017;24: 3591-3618.

10. Gulati I, Park J, Maken S, Lee MG. Production of Carboxymethyl cellulose fibers from waste lignocellulosic sawdust using $\mathrm{NaOH} / \mathrm{NaClO}_{2}$ pretreatment. Fibers Polym. 2014;15:680-686.

11. Kumar H, Gaur A, Kumar S, Park JW. Development of silver nanoparticles-loaded CMC hydrogel using bamboo as a raw material for special medical applications. Chem. Pap. 2018.

12. Mondal MIH, Yeasmin MS, Rahman MS. Preparation of food grade carboxymethyl cellulose from corn husk agrowaste. Int. J. Biol. Macromol. 2015;79:144-150.

13. Su JF, Huang Z, Yuan XY, Wang XY, Min L. Structure and properties of carboxymethyl cellulose/soy protein isolate blend edible films cross-linked by Maillard reactions. Carbohydr. Polym. 2010;79:145-153.

14. Joshi G, Naithani S, Varshney VK, Bisht SS, Rana V, Gupta PK. Synthesis and characterization of carboxymethyl cellulose from office waste paper: A greener approach towards waste management. Waste Manage. 2014;38:33-40.

15. Mohkami M, Talaeipour M. Investigation of the chemical structure of carboxylated and carboxymethylated fibers from waste paper via XRD and FTIR analysis. Bio Resources 2011;6: 1988-2003.

16. Togrul H, Arslan N. Production of carboxymethyl cellulose from sugar beet pulp cellulose and rheological behavior of carboxymethyl cellulose. Carbohydr. Polym. 2003;54:73-82.

17. Mohsenabadi N, Rajaei A, Tabatabaei M, Mohsenifar A. Physical and antimicrobial properties of starch-carboxy methylcellulose film containing rosemary essential oils encapsulated in chitosan naogel. Int. J. Biol. Macromol. 2018;112:148-155.

18. Ma W, Tang CH, Yin SW, Yang XQ, Qi JR, Xia N. Effect of homogenization conditions on properties of gelatin-olive oil composite films. J. Food Eng. 2012;113:136-142.

19. Ghanbarzadeh B, Almasi H, Entezami AA. Physical properties of edible modified starch/carboxymethyl cellulose films. Innov. Food Sci. Emerg. Technol. 2010;11:697-702.

20. Koo SH, Lee KY, Lee HG. Effect of cross-linking on the physicochemical and physiological properties of corn starch. Food Hydrocolloid. 2010;24:619-625.

21. Mali S, Grossmann MVE, Garcia MA, Martino MN Zaritzky NE. Effects of controlled storage on thermal, mechanical and barrier properties of plasticized films from different starch sources. J. Food Eng. 2006;75:453-460.

22. Rodsamran P, Sothornvit R. Rice stubble as a new biopolymer source to produce carboxymethyl cellulose-blended films. Carbohydr. Polym. 2017;171:94-101.

23. Jouki M, Khazaei N, Ghasemlou M, Hadinezhad M. Effect of glycerol concentration on edible film production from cress seed carbohydrate gum. Carbohydr. Polym. 2013;96:39-46.

24. Ilyas RA, Sapuan SM, Ishak MR. Isolation and characterization of nanocrystalline cellulose from sugar palm fibres (Arenga Pinnata). Carbohydr. Polym. 2018;181:1038-1051.

25. AOAC, Office methods of analysis of AOAC International. 17th eds. Gaithersburg MD: Association of Official Analytical Chemists. c2002. Available From: https://www.chemicalbook. com/ChemicalProductProperty_EN_CB72096013.htmm.

26. Pereda M, Amica G, Marcovich NE. Development and characterization of edible chitosan/olive oil emulsion films. Carbohydr. Polym. 2012;87:1318-1325.

27. Saputra AH, Qadhayna L, Pitaloka AB. Synthesis and characterization of carboxymethyl cellulose (CMC) from water Hyacinth using Ethanol-Isobutyl Alcohol Mixture as the solvents. Int. J. Chem. Eng. Appl. 2014;5:36-40.

28. Spychaj T, Wilpiszewska K, Zdanowicz M. Medium and high substituted carboxymethyl starch: Synthesis, characterization, and applications. Starch-Starke 2013;65:22-33.

29. Gu H, He J, Huang Y, Guo Z Water-soluble Carboxymethylœellulosefibers polymers derived from alkalization-etherification of viscose fibers. Fibers Polym. 2012;13:748-753.

30. Rachtanapun P, Rattanapanone N. Synthesis and character- 
ization of carboxymethyl cellulose powder and films from Mimosa pigra. J. Appl. Polym. Sci. 2011;122:3218-3226.

31. Yeasmin MS, Mondal MIH. Synthesis of highly substituted carboxymethyl cellulose depending on cllulose particle size. Int. J. Biol. Macromol. 2015;80:725-731.

32. Dick M, Costa TMH, Gomaa A, Subirade M, Rios ADO, Flores
SH. Edible film production from chia seed mucilage: Effect of glycerol concentration on its physicochemical and mechanical properties. Carbohydr. Polym. 2015;130:198-205.

33. Asl SA, Mousavi M, Labbafi M. Synthesis and characterization of carboxymethyl cellulose from sugarcane bagasse. J. food Proc. Technol. 2017;8:687-692. 